\title{
The Effects of Controversial Reviews on Product Sales Performance: The Mediating Role of the Volume of Word of Mouth
}

\author{
KungHsin Shao ${ }^{1}$ \\ ${ }^{1}$ College of Management, National Taiwan University, Taipei, Taiwan \\ Correspondence: KungHsin Shao, College of Management, National Taiwan University, 1, Sec. 4, Roosevelt Rd. \\ Taipei, Taiwan. Tel: 886-2-3366-4983. E-mail: asukaa1@gmail.com
}

Received: May 16, 2012 Accepted: May 28, 2012 Online Published: July 25, 2012

doi:10.5539/ijms.v4n4p32 URL: http://dx.doi.org/10.5539/ijms.v4n4p32

\begin{abstract}
The influence of word of mouth (WOM) is increasing even with today's advanced Internet environment.Although previous studies indicate no consensus on the impact of the valence of WOM on product sales, manufacturers often make use of a variety of ways to correct the direction of the valence of WOM because they want to have a good reputation on the Internet.The question that arises is whether negative WOM has a completely negative impact on product sales. This study usesthe beta distribution to capture the variety of review structures, especially controversial review structures. By verifying the mediation effect of the volume of WOM, we found that products with controversial reviews could arouse a huge amount of discussion among consumers that eventually translates into product sales. The study therefore suggests that manufacturers need not aim to eliminate the spread of negative WOM but should aim to keep it at a moderate level.
\end{abstract}

Keywords: online user reviews, word of mouth, review structures, two-way persuasion, mediation analysis

\section{Introduction}

The influence of word of mouth (WOM) is increasing even with today's advanced Internet environment. According to one survey, more than $60 \%$ of consumers in the United States would consult online reviews from other consumerswhen making a purchase decision (Razorfish.com. 2008). It is therefore not surprising that manufacturers have started to focus on online WOM and some of them even want to manipulate it (Dellarocas, 2006; Godes \& Mayzlin, 2009).

Most previous studies of online WOM explore the impact of characteristics of online WOM on product sales (Chevalier \& Mayzlin, 2006; Chintagunta, Gopinath, \&Venkataraman, 2010; Dellarocas, Zhang, \& Awad, 2007; Duan, Gu, \& Whinston, 2008; Liu, 2006; Moon, Bergey, \& Iacobucci, 2009; Zhu \& Zhang, 2010), especially for the impact of the valence of WOM and the volume of WOM. Theoretically, both characteristics of online WOM have different effects on product sales (Liu, 2006). The valence of WOM affects consumers' attitudes toward a product, while the volume of WOM affects consumers' awareness of a product, both of which affect consumers' purchasing behavior. The influence of the volume of WOM on product sales is less debatable and produces apositive effect (Anderson \& Salisbury, 2003; Duan et al., 2008; Liu, 2006). There is nevertheless a controversy on the impact of the valence of WOM on product sales. Some studies suggest that the valence of WOM does have a positive impact on product sales (Chevalier \& Mayzlin, 2006; Dellarocas \& Narayan, 2006; Godes \& Mayzlin, 2004), but others indicate that the valence of WOM does not affect product sales (Duan et al., 2008; Liu, 2006).

Although there is no consensus on the impact of the valence of WOM on product sales, manufacturers often make use of a variety of ways to correct the direction of the valence of WOM because they want to have a good reputation on the Internet. Nevertheless, the extent to which negative WOM has a completely negative impact on product sales remains unclear. According to the arguments from two-sided persuasion, delivering a partial negative message would have a more persuasive effect than using only positive messages while advertising (Etgar\& Goodwin, 1982; Golden \& Alpert, 1987; Pechmann, 1992). In other words, when the consumer receives two-sided messages in the evaluation of a particular product, it is likely to enhance the consumer's preference for the product and thus increase his/her purchase intention, but only a few WOM studiesinclude the two-sided WOM intheir models. Jen, Shao, and Tien, (2011), for example, found that the controversial review structure is able to attract more imitators (q, imitator coefficient) to purchase products. 
This study seeks to verify three issues. First, does the effect of the valence of WOM on product sales exist or not? Second, do controversial reviews really help product sales? Third, what role does the volume of WOM play in the process of WOM communication? Does it act as a mediator between the valence of WOM or review structure and product sales, or is it simply an influencingfactor? We discuss this in the following section.

\section{Conceptual Framework and Hypotheses}

Figure 1 illustrates our conceptual framework. We try not only to validate the impacts of the three characteristicsof WOM (the valence of WOM, the volume of WOM, and review structures) on product sales but also confirm the mediator role that the volume of WOM plays.

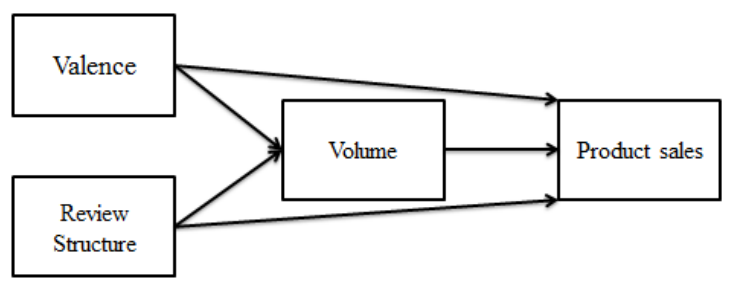

Figure 1. Conceptual framework: the word-of-mouth communication process

As noted in the introduction, one previous study argues that a greater volume of WOM would increase consumer awareness of a specific product and therebyincrease the product sales (Liu, 2006). This argument is proven by most studies (Duan et al., 2008; Liu, 2006), but the relationship between the valence of WOM and product sales is mixed. Some studies report that the valence of WOM has a positive influence on product sales (Chevalier \& Mayzlin, 2006; Dellarocas \& Narayan, 2006; Godes \& Mayzlin, 2004) but others assert that the valence of WOM is not an important factor in product sales (Duan et al., 2008; Liu, 2006). We hypothesize that the valence of WOM would have a positive impact on product sales.

Next, we would discuss the relationship between the valence of WOM and the volume of WOM. Previous studies argue that when the valence of WOM is high, according to the expectancy disconfirmation theory, some consumers would easily feel dissatisfied. These dissatisfied consumers would have higher motivation to spread negative WOM to reduce their anxiety or for the purpose of vengeance. There are also satisfied consumers willing to spread positive WOM out of altruism and self-enhancement (Duan et al., 2008; Wangenheim \& Bayon, 2004).

Previous studies have measured the valence of WOM either by the average review ratings or by classifying reviews into positive and negative WOM to verify the impact of the valence of WOM on product sales, but they rarely investigate the impact of two-sided WOM on product sales. Many studies have already shown the effect of two-sided persuasion (Crowley \& Hoyer, 1994; Kamins, Brand, Hoeke, \& Moe, 1989). Crowley and Hoyer (1994) summarized the previous literature and proposed three possible mechanisms to explain why two-sided persuasion is effective. The first is the attribution theory, which indicates that it is more likely for consumers to believe two-way messages and thus develop a more positive attitude toward the brand (Jones \& Davis, 1966; Kelley, 1973). The second is the inoculation theory, which holds that when the advertiser delivers both positive and negative messages to consumers and then refutes these negative arguments immediately, consumers would learn to contradict the counter claims before long. (McGuire, 1961). The third is the optimal arousal theory, which suggests that advertising with two-way messages stimulate consumer curiosity and motivate the consumer to process these messages, ultimately enhancing the attractiveness of the advertising and product (Berlyne, 1971).

Finally, although some studies assert that the valence of WOM is positively associated with the volume of WOM, which in turn generates higher product sales (Duan et al., 2008; Ekaterina, 2011), they do not validate it by mediation analysis. We propose the following hypotheses:

H1: The valence of WOM has a positive influence on product sales, but the influence has mediated by the volume of WOM.

H2: Controversial review structures generate higher product sales than other review structures, but the impactis mediated by the volume of WOM. 


\section{Method}

\subsection{Measuring Review Structures}

This study, following Jen, Shao, and Tien (2011), models review structures by using the beta distribution. The probability density function $(p d f)$ of the beta distribution is as follows:

$$
f(x)=x^{\alpha-1}(1-x)^{\beta-1} / B(\alpha, \beta), x \in(0,1)
$$

The beta distribution is a continuous probability distribution with the following characteristics: (1) it is used to describe a random variable with a value ranging from 0 to 1 ; (2) it is very flexible because it contains two positive shape parameters: alpha and beta. With different combinations of these two parameters, we can obtain different density curves that can be used to represent different review structures. If these two parameters are less than 1 , the density curve will look like a U-shaped curve, which can be viewed as a controversial review structure. If alpha is greater than 1 and beta less than 1, the density curve becomes a J-shaped one, which can be regarded as a positive review structure. If the alpha is less than 1 and beta greater than 1 , the density curve will be a mirror image of the J-shaped curve, which could be represented as a negative review structure. Finally, if both parameters are greater than 1 , the density curve will be an inverted U-shaped one, which can be viewed as a prosaic review structure.

\subsection{Mediation Analysis}

This study follows the mediation analysis process put forward by Baron and Kenny (1986). The analysis process includes four steps:

Step 1: Show that the initial explanatory variable is significantly associated with the dependent variable. If the relationship is confirmed, then there is an effect that may be mediated.

Step 2: Show that the initial explanatory variable significantly affects the mediator.

Step 3: Show that the mediator is significantly correlated with the dependent variable.

Step 4: Consider the effects of both the initial explanatory variable and mediator on the dependent variable at the same time. Show that the initial explanatory variable has no relationship with the dependent variable.

If all the four steps are fulfilled, then we can declare that the mediator completely mediates the relationship between the initial explanatory variable and the dependent variable.

\subsection{Data}

We chose the motion picture industry as our research object. We first determined the movies that we rereleased in the U.S. in 2009 according to IMDB.com (www.imdb.com) and chose the top 150 movies for our sample. The user review data are also collected from IMDB.com. Other data, including box-officesales, number of theaters, genre, and the Motion Picture Association of America (MPAA) ratings, are collected from Boxofficemojo.com (www.boxofficemojo.com).

All data for the movie samples are time-variant data except movie genre and MPAA ratings. We organize the box-office, number of theaters, and user reviews in a weekly pattern. Some movies are further excluded from our sample because the releaseperiods are too short (less than 8 weeks). Our final sample consists of 104 movies. We then aggregate the box-office sales, number of theaters, and user review data from week 1 to week 8 for each movie. The summary information canbe viewed in Table 1 .

Table 1. Summary statistics of the movie sample

\begin{tabular}{lrrrr}
\hline & Mean & Std. & Min. & Max. \\
\hline Box-office (millions of & 83.38 & 93.17 & 8.70 & 637.61 \\
U.S.\$) & & & & \\
No. of theaters & 13260.16 & 6229.97 & 3123.00 & 26291.00 \\
Volume & 162.99 & 240.70 & 18.00 & 1774.00 \\
Valence & 6.17 & 1.07 & 3.43 & 8.75 \\
Total number of movies = 104 & & & & \\
\hline
\end{tabular}

According to the estimation based on the beta distribution, we categorize review structures as controversial 
review, positive review, negative review, or prosaic review. By accumulating all the user reviews in 8 weeks for each movie, 21 movies would be classified in the controversial review structure (see Table 2).

Following previous studies, movie genre and MPAA ratings are often used as control variables in our model. For the movie genre, there are 24 action or adventure movies (abbreviated as act/adv), 27 comedy movies (abbreviated as com), 20 drama movies (abbreviated as dra), and 23 horror or thriller movies (abbreviated as hor/thr); the rest of the movies are classifiedas other genre (genre-others). For the MPAA ratings, we simply classify the ratings as restricted movies (MPAA-R) and non-restricted movies (MPAA-NR). All summaries of classification are also shown in Table 2.

Table 2. Classification of movie characteristics

\begin{tabular}{llc}
\hline Movie characteristic & & No of movies \\
\hline Review structures & controversial review & 21 \\
& others & 83 \\
Genre & act/adv & 24 \\
& com & 27 \\
& dra & 20 \\
& hor/thr & 23 \\
MPAA & genre-others ${ }^{1}$ & 20 \\
& MPAA-R & 35 \\
& MPAA-NR & 69 \\
\hline
\end{tabular}

Note: ${ }^{1}$ Includes animation \& concert ${ }^{2}$ Includes G, PG, and PG-13

\section{Result}

To prevent the bias of linear regression caused by extreme values in the samples, this study uses the log-linear formulation (Duan et al., 2008; Elberse \& Eliashberg, 2003; Liu, 2006). The box-office receipts, valence, volume, and number of theaters are log-transformed. To verify the mediator role played by the volume of WOM, the subsequent steps in theanalysis are based on the recommendations of Baron and Kenny (1986) with results shown in Table 3.

Table 3. Estimation result for path analysis

\begin{tabular}{|c|c|c|c|c|c|c|c|c|}
\hline \multirow{3}{*}{ variables } & \multicolumn{8}{|c|}{ Dependent variable } \\
\hline & \multicolumn{2}{|c|}{ S1: ln_box-office } & \multicolumn{2}{|c|}{ S2: ln_volume } & \multicolumn{2}{|c|}{ S3: ln_box-office } & \multicolumn{2}{|c|}{ S4 : ln_box-office } \\
\hline & Coef. & P-value & Coef. & P-value & Coef. & P-value & Coef. & P-value \\
\hline Ln_valence & 0.026 & 0.593 & -0.008 & 0.935 & & & 0.028 & 0.506 \\
\hline Ln_volume & & & & & 0.265 & 0.000 & 0.264 & 0.000 \\
\hline Controversial review & 0.074 & 0.076 & 0.253 & 0.002 & & & 0.007 & 0.847 \\
\hline Ln_no. of theaters & 0.902 & 0.000 & 0.545 & 0.000 & 0.767 & 0.000 & 0.758 & 0.000 \\
\hline Act_Adv & 0.035 & 0.621 & 0.241 & 0.081 & -0.044 & 0.440 & -0.029 & 0.648 \\
\hline Com & -0.015 & 0.842 & -0.149 & 0.298 & 0.011 & 0.848 & 0.025 & 0.702 \\
\hline Dra & 0.019 & 0.768 & 0.090 & 0.477 & -0.014 & 0.803 & -0.005 & 0.936 \\
\hline Hor & -0.046 & 0.539 & 0.073 & 0.612 & -0.081 & 0.164 & -0.065 & 0.314 \\
\hline Mpaa_R & 0.035 & 0.445 & 0.239 & 0.007 & -0.021 & 0.569 & -0.028 & 0.484 \\
\hline $\mathrm{R}^{2}$ & \multicolumn{2}{|c|}{0.854} & \multicolumn{2}{|c|}{0.581} & \multicolumn{2}{|c|}{0.891} & \multicolumn{2}{|c|}{0.892} \\
\hline
\end{tabular}

Note: All the coefficients are standardized coefficients. 
Step1.

From the results of step1 (S1), we need to verify that the initial explanatory variable is significantly associated with the dependent variable.In our model, we have two initial explanatory variables: In_valence and controversial review. The coefficient of $\ln \_$valence is 0.026 ( $\mathrm{p}$-value $>0.05$ ), which shows that $\overline{l n}$ _valencehas little impact on ln_box-office. The coefficient of controversial review is 0.074 ( $p$-value $<0.1$ ), which shows that controversial review has a significantly positive impact on ln_box-office. This result means that positive WOM does not seem to generate higher box-office sales; instead, controversial reviews of a film will create higher box-office sales than other types of review structures.

Step2.

In step 2 (S2), we need to show that the initial explanatory variable significantly affects the mediator. The coefficient of ln_valence is -0.008 ( $p$-value $>0.05$ ), which shows that ln_valencehas no influence on ln_volume. The coefficient of controversial review is 0.253 (p-value $<0.05$ ), which shows that controversial review has a significantly positive impact on ln_box-office. This result means the positive WOMdoes not increase the volume of WOM; on the other hand, controversial reviewswill arouse more consumer discussion and increase the volume of WOM.

Step3.

In step3 (S3), we need to show that the mediator significantly is correlated with the dependent variable. The result shown in S3, undoubtedly, is that the relationship between ln_volume and ln_box-office is positively significant (the coefficient is 0.265 and the p-value $<0.001$ ).

Step4.

In the final step, we need to show that the initial explanatory variable has no relationship with the dependent variable when considering the effects of both the initial explanatory variable and mediator on the dependent variable at the same time. Hence, under the setting in S1, we put ln_volume into the model. The result is shown in S4. We still find that ln_valence is not associated with ln_box-office, but the coefficient of controversial review decreases from 0.074 in $\mathrm{S} 1$ to 0.007 in $\mathrm{S} 4$ andchanges from significant (p-value $<0.1)$ to insignificant ( $\mathrm{p}$-value $>0.05$ ). At the same time, the coefficient ofln_volumeis 0.264 , whichstill has a positive and significant impact on ln_box-office.

The final results of mediation analysis are summarized in Figure 2. The impact ofcontroversial reviews on volume is significantly positive. Volume is also positively associated with box-office. As regards the relationship between controversial review and box-office, before the volume isincluded, controversial review has a positive and significant impact on box-office, but the positive effect reverses to no effect after the volumeis included. Hence, $\mathrm{H} 2$ is supported, but $\mathrm{H} 1$ is not. We can therefore conclude that volume would completely mediate the relationship between controversial review and box-office.

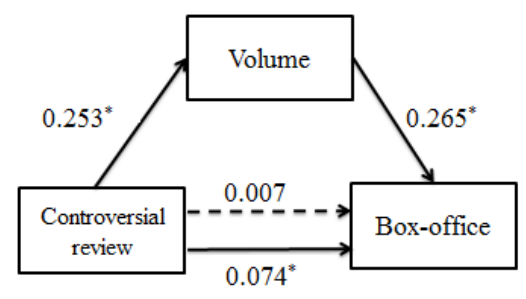

Figure 2. The result of mediation analysis

\section{Conclusion}

When previous studies investigate the impact of WOM on product sales, most of them argue that only the volume of WOM, but not the valence of WOM, has a significant effect on product sales performance. Some studies nevertheless suggest that the valence of WOM may still havean indirect impact on product sales through the volume of WOM. In addition, previous studies have rarely mentioned the impact of review structures on product sales. 
This study attempts to take advantage of the characteristics of the beta distribution to divide all reviews into two types, those with a controversial review structure and those with a non-controversial review structure, and to verify the mediation effect of the volume of WOM by putting review structures into the model. Interestingly, we found that the volume of WOM has indeed been a mediator to the impact on product sales, but the volume of WOM does not mediate the effect from the valence of WOM on product sales; instead, it mediates the effect of review structures on product sales. In other words, products with controversial reviews could stimulate a huge amount of discussion among consumers that will eventually be translated into product sales.

Manufacturers are always afraid of negative WOM spreading on the Internet, assuming that this will negatively affect product sales. According to the findings of this study, controversial reviews have a positive impact on final product sales, and negative WOM is in fact not entirely harmful. Manufacturers, therefore, should not try to eliminate the spread of negative WOM but should seek to keep it to a moderate level.

Although we have verified the benefit of controversial reviews, whether such benefit increases or decreases along the evolution of the product life cycle is a question that remains to be discussed. In the research sample, moreover, this study has taken into consideration only the film industry, in which the normal product life cycle is more rapid and transient than in other areas. Further research is therefore recommended on other general goods to verify the results presented in this study.

\section{References}

Anderson, E. W., \& Salisbury, L. C. (2003). The formation of market-level expectations and its covariates. Journal of Consumer Research, 30(1), 115-124. http://dx.doi.org/10.1086/374694

Baron, R. M., \& Kenny, D. A. (1986). The moderator-mediator variable distinction in social psychological research: Conceptual, strategic, and statistical considerations. Journal of Personality and Social Psychology, 51(6), 1173-1182. http://dx.doi.org/10.1037/0022-3514.51.6.1173

Berlyne, D. E. (1971). Aesthetics and psychobiology. East Norwalk, CT: Appleton-Century-Crofts.

Chevalier, J. A., \& Mayzlin, D. (2006). The effect of word of mouth on sales: Online book reviews. Journal of Marketing Research, 43(3), 9. http://dx.doi.org/10.1509/jmkr.43.3.345

Chintagunta, P. K., Gopinath, S., \& Venkataraman, S. (2010). The effects of online user reviews on movie box office performance: Accounting for sequential rollout and aggregation across local markets. Marketing Science, 29(5), 944-957. http://dx.doi.org/10.1287/mksc.1100.0572

Crowley, A. E., \& Hoyer, W. D. (1994). An integrative framework for understanding two-sided persuasion. Journal of Consumer Research, 20(4), 561-574. http://dx.doi.org/10.1086/209370

Dellarocas, C. (2006). Strategic manipulation of Internet opinion forums: Implications for consumers and firms. Management Science, 52(10), 1577-1593. http://dx.doi.org/10.1287/mnsc.1060.0567

Dellarocas, C., \& Narayan, R. (2006). A statistical measure of a population's propensity toengage in $\begin{array}{llll}\text { post-purchase online } \quad \text { word-of-mouth. Statistical } & \text { Science, 21(2), }\end{array}$ http://dx.doi.org/10.1214/088342306000000169

Dellarocas, C., Zhang, X., \& Awad, N. F. (2007). Exploring the value of online product reviews in forecasting sales: The case of motion pictures. Journal of Interactive Marketing, 21(4), 23-45. http://dx.doi.org/10.1002/dir.20087

Duan, W., Gu, B., \& Whinston, A. B. (2008). The dynamics of online word-of-mouth and product sales-An empirical investigation of the movie industry. Journal of Retailing, 84(2), 233-242. http://dx.doi.org/10.1016/j.jretai.2008.04.005

Ekaterina V, K. (2011). Impact of star and movie buzz on motion picture distribution and box office revenue. $\begin{array}{lllll}\text { International Journal of Research in } & \text { Marketing, }\end{array}$ http://dx.doi.org/10.1016/j.jiresmar.2010.10.001

Elberse, A., \& Eliashberg, J. (2003). Demand and supply dynamics for sequentially released products in international markets: The case of motion pictures. Marketing Science, 22(3), 329-354. http://dx.doi.org/10.1287/mksc.22.3.329.17740

Etgar, M., \& Goodwin, S. A. (1982). One-sided versus two-sided comparative message appeals for new brand introductions. Journal of Consumer Research, 8(4), 460-465. http://dx.doi.org/10.1086/208888

Godes, D., \& Mayzlin, D. (2004). Using Online Conversations to Study Word-of-Mouth Communication. Marketing Science, 23(4), 545. http://dx.doi.org/10.1287/mksc.1040.0071 
Godes, D., \& Mayzlin, D. (2009). Firm-created word-of-mouth communication: Evidence from a field test. Marketing Science, 28(4), 721-739. http://dx.doi.org/10.1287/mksc.1080.0444

Golden, L. L., \& Alpert, M. I. (1987). Comparative analysis of the relative effectiveness of one- and two-sided communication for contrasting products. Journal of Advertising, 16(1), 18-25.

Jen, L., Shao, K., \& Tien, H. (2011). A new approach to measure the valence of WOM [Working Paper]. Department of International Business, National Taiwan University.

Jones, E. E., \& Davis, K. E. (1966). From acts to dispositions: The attribution process in person perception. In B. Leonard (Ed.), Advances in experimental social psychology (Vol. 2, pp. 219-266). New York, NY: Academic Press.

Kamins, M. A., Brand, M. J., Hoeke, S. A., \& Moe, J. C. (1989). Two-sided versus one-sided celebrity endorsements: The impact on advertising effectiveness and credibility. Journal of Advertising, 18(2), 4-10.

Kelley, H. H. (1973). The processes of causal attribution. American Psychologist, 28(2), $107-128$. http://dx.doi.org/10.1037/h0034225

Liu, Y. (2006). Word of mouth for movies: Its dynamics and impact on box office revenue. Journal of Marketing, 70(3), 74-89. http://dx.doi.org/10.1509/jmkg.70.3.74

McGuire, W. J. (1961). The effectiveness of supportive and refutational defenses in immunizing and restoring beliefs against persuasion. Sociometry, 24(2), 184-197. http://dx.doi.org/10.2307/2786067

Moon, S., Bergey, P. K., \& Iacobucci, D. (2009). Dynamic effects among movie ratings, movie revenues, and viewer satisfaction. Journal of Marketing, 74(1), 108-121. http://dx.doi.org/10.1509/jmkg.74.1.108

Pechmann, C. (1992). Predicting when two-sided ads will be more effective than one-sided ads: The role of correlational and correspondent inferences. Journal of Marketing Research, 29(4), 441-453. http://dx.doi.org/10.2307/3172710

Razorfish.com. (2008). Digital consumer behavior study. Retrieved from www.razorfish.com/reports/DigConsStudy.pdf

Wangenheim, F. V., \& Bayon, T. (2004). The effect of word of mouth on services switching: Measurement and moderating variables. European Journal of Marketing, 38(9/10), 1173-1185. http://dx.doi.org/10.1108/03090560410548924

Zhu, F., \& Zhang, X. (2010). Impact of online consumer reviews on sales: The moderating role of product and consumer characteristics. Journal of Marketing, 74(2), 133-148. http://dx.doi.org/10.1509/jmkg.74.2.133 